\title{
Outcomes, readmissions, and costs in transfemoral and alterative access transcatheter aortic valve replacement in the US Medicare population
}

Fenton H. McCarthy, MD, MS, ${ }^{\mathrm{a}, \mathrm{b}}$ Danielle D. Spragan, MD, ${ }^{\mathrm{b}}$ Danielle Savino, BS, ${ }^{\mathrm{b}}$ Taylor Dibble, BS, ${ }^{\mathrm{b}}$ Ashley C. Hoedt, BS, MS, ${ }^{\mathrm{b}}$ Katherine M. McDermott, BS, ${ }^{\mathrm{b}}$ Joseph E. Bavaria, MD, ${ }^{\mathrm{b}}$ Howard C. Herrmann, MD, ${ }^{c}$ Saif Anwaruddin, MD, ${ }^{c}$ Jay Giri, MD, ${ }^{c}$ Wilson Y. Szeto, MD, ${ }^{b}$ Peter W. Groeneveld, MD, MS, ${ }^{\mathrm{a}, \mathrm{d}, \mathrm{e}}$ and Nimesh D. Desai, MD, $\mathrm{PhD}^{\mathrm{a}, \mathrm{b}}$

\section{ABSTRACT}

Objective: To comprehensively evaluate and compare utilization, outcomes, and especially costs of transfemoral (TF), transapical (TA), and transaortic (TAO) transcatheter aortic valve replacement (TAVR).

Methods: All Medicare fee-for-service patients undergoing TF $(n=4065)$, TA $(\mathrm{n}=691)$, or TAO $(\mathrm{n}=274)$ TAVR between January 1,2011 , and November 30, 2012, were identified using Health Care Procedure Classification Codes present on Medicare claims. Hospital charges from Medicare claims were converted to costs using hospital-specific Medicare cost-to-charge ratios.

Results: TA and TAO patients were similar in age, race, and common comorbidities. Compared with TF patients, TA and TAO patients were more likely to be female and to have peripheral vascular disease, chronic lung disease, and renal failure. Thirty-day mortality rates were higher among TA and TAO patients than among TF patients (TA, 9.6\%; TAO, 8.0\%; TF, 5.0\%; $P<.001$ ). Adjusted mortality beyond 1 year did not differ by access. TA patients were more likely to require cardiopulmonary bypass (CPB). Increased adjusted mortality was associated with CPB (hazard ratio, 2.13; $P<.01$ ) and increased 30-day cost (\$62,000 [interquartile range (IQR)], $\$ 45,100-\$ 86,400$ versus $\$ 48,800$ [IQR, $\$ 38,100-\$ 62,900] ; P<.01)$. Cost at 30 days was lowest for TF $(\$ 48,600)$ compared with TA $(\$ 49,800 ; P<.01)$ and TAO $(\$ 53,200 ; P=.03)$.

Conclusions: For patients ineligible to receive TF TAVR, TAO and TA approaches offer similar clinical outcomes at similar cost with acceptable operative and 1-year survival, except for higher rates of CPB use in TA patients. CPB was associated with worse survival and increased costs. (J Thorac Cardiovasc Surg 2017;154:1224-32)

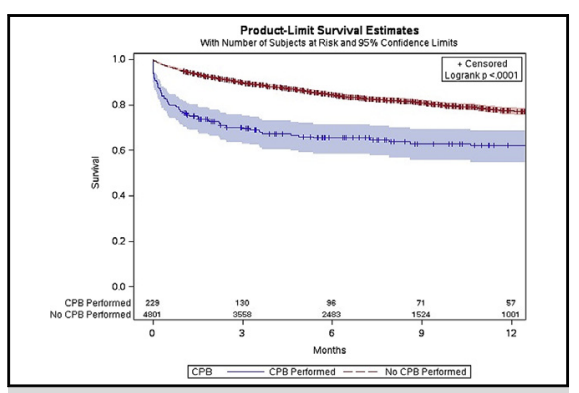

Kaplan-Meier survival estimates for TAVR patients by use of cardiopulmonary bypass.

\section{Central Message}

The need for CPB bypass in TAVR is associated with TA access, worse outcomes and increased cost.

\section{Perspective}

Short-term outcomes and costs vary by TAVR access, with increased use of cardiopulmonary bypass, mortality and costs in TA TAVR. Readmission rates were similar by TAVR access at 90 days. The use of cardiopulmonary bypass was associated with worse survival and increased costs for all TAVR accesses.

See Editorial Commentary page 1233.
Transcatheter aortic valve replacement (TAVR) for severe aortic stenosis has demonstrated significant clinical benefit in large randomized trials compared with both medical management and at least equivalent results compared with

From the ${ }^{\mathrm{a}}$ Leonard Davis Institute of Health Economics, Divisions of ${ }^{\mathrm{b}}$ Cardiovascular Surgery and ${ }^{\mathrm{c}}$ Cardiology, and ${ }^{\mathrm{d}}$ Department of Medicine, University of

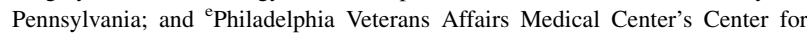
Health Equity Research and Promotion, Philadelphia, Pa.

Read at the 96th Annual Meeting of The American Association for Thoracic Surgery, Baltimore, Maryland, May 14-18, 2016.

Received for publication May 27, 2016; revisions received March 13, 2017; accepted for publication April 8, 2017; available ahead of print July 13, 2017.

Address for reprints: Nimesh D. Desai, MD, PhD, Division of Cardiovascular Surgery, Hospital of the University of Pennsylvania, 3400 Spruce St, 6th Floor Silverstein, Philadelphia, PA 19104 (E-mail: Nimesh.Desai@uphs.upenn.edu). 0022-5223/\$36.00

Copyright @ 2017 Published by Elsevier Inc. on behalf of The American Association for Thoracic Surgery

http://dx.doi.org/10.1016/j.jtcvs.2017.04.090 surgical aortic valve replacement (SAVR) in patients of intermediate or greater risk. ${ }^{1-7}$ TAVR technology has been rapidly adopted across the United States, with comparable results in commercial use and clinical trials. ${ }^{5,8}$ The initial structure of the TAVR clinical trials in the United States and approval from the Food and Drug Administration required that a heart team evaluate each patient as a candidate for a transfemoral (TF) TAVR approach before considering a transapical (TA) or transaortic (TAO)

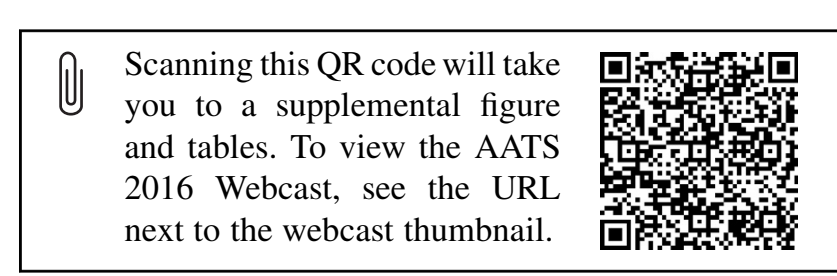




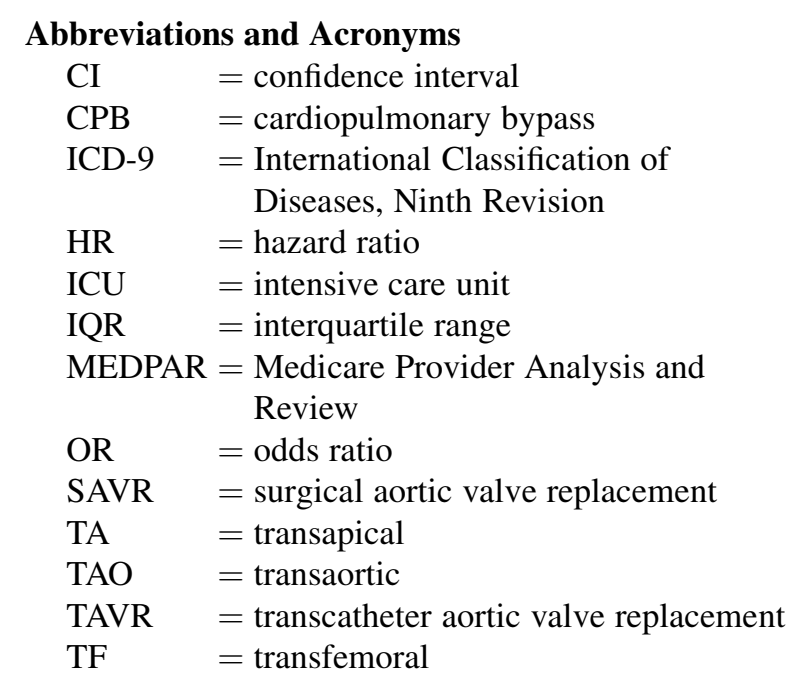

approach. ${ }^{1,2}$ Yet, the proportion of patients undergoing TF TAVR in the United States still differs from that in Europe, with the TF access approach used in only $55 \%$ of US cases between November 2011 and June 2013, compared with $72.8 \%$ of cases in the United Kingdom between 2011 and 2012. ${ }^{9,10}$

Although the use of alternative approaches in US centers has declined recently with the introduction of newer valve prostheses and lower-profile insertion sheaths, studies still demonstrate that a significant number of patient in the United States are not candidates for TF TAVR. ${ }^{6,7}$ While non-TF access has been associated with increased mortality in clinical trials and commercial TAVR use, the degree to which baseline differences in the patient populations influence this finding remains unclear. ${ }^{2,6,7}$ In patients undergoing alternative TAVR access approaches, previous studies have identified notable differences between TA and TAO in terms of the preoperative risk profiles of the patient populations, with the worse outcomes in the TAO group driven primarily by patients with the highest Society of Thoracic Surgeons scores. ${ }^{11}$ There has also been significant variability when evaluating the cost-effectiveness of TAVR, depending on the nationality of the health system, the TAVR access (TA vs TF), and the comparison group (medical management vs SAVR).

The purpose of this study was to evaluate and compare mortality, cost, discharge disposition, and readmission data stratified by TAVR access among TF, TA, and TAO TAVR in the US Medicare population.

\section{METHODS}

\section{Study Sample and Medicare Data}

The study was approved by the Intuitional Review Board at the University of Pennsylvania. All Medicare fee-for-service patients undergoing TF $(\mathrm{n}=4065)$, TA $(\mathrm{n}=691)$, or TAO $(\mathrm{n}=274)$ TAVR between January 1 , 2011, and November 30, 2012 were identified using Health Care Procedure Classification Codes present on Center for Medicare and Medicaid Services carrier claims. The codes for TF, TA, and TAO were 0256T, 0257T, and 0258T, respectively. The access approach for TAVR is determined preoperatively by the heart team at each individual institution. All patients were linked to data in Medicare denominator files to collect age, race, and sex data. Comorbidities with $>5 \%$ prevalence in the cohort-ie, hypertension, congestive heart failure, peripheral vascular disease, iron deficiency anemia, chronic pulmonary disease, chronic kidney disease, diabetes mellitus, and liver disease-were identified by applying a modified Elixhauser comorbidity index to International Classification of Diseases, Ninth Revision (ICD-9) diagnosis codes to diagnose conditions that were present on admission at the index hospitalization for TAVR or were listed on a Medicare claim in the year preceding the patient's index hospitalization. ${ }^{12,13}$ ICD-9 procedure codes present on index hospitalization were used to identify cardiopulmonary bypass (CPB) using ICD-9 codes 39.61 and 39.66. Mortality data were collected by linking index hospitalization records to death records in Medicare denominator files.

\section{Cost and Payment Data}

Hospital charges and Medicare payments were collected from Medicare's Medicare Provider Analysis and Review (MEDPAR) (inpatient hospitalization) files, which represent final action (ie, completely adjudicated) claims on individual patient hospitalizations. This payment also accounts for the post-acute care payment adjustment-sometimes referred to as a "transfer penalty"-which can potentially result in a diagnosis related group-specific downweighting of reimbursement for admissions that are shorter relative to the national geometric mean length of stay. Hospital charges, which are subdivided into 30 hospital cost centers on MEDPAR claims, indicate each hospital departmental (eg, radiology), resource (eg, blood bank), and accommodation (eg, ward) charge for care provided during the index TAVR admission. Payments, which are reported separately on MEDPAR claims as patient payments, private insurance payments, and Medicare payments, were also abstracted.

Hospital charges were converted to cost of care using hospital-specific cost-to-charge ratios from the 2015 Inpatient Prospective Payment System Impact File, which represents cost-to-charge ratios calculated using 2012 Center for Medicare and Medicaid Services cost data. Cost of care was therefore an estimation of a hospital's total expenditures for each TAVR hospitalization. The use of these data in Medicare cost analyses has been previously validated. ${ }^{14}$

\section{Statistical Analysis}

Categorical variables were analyzed using Fisher's exact test, and continuous variables were analyzed using the 2 -sample $t$ test. The Mann-Whitney nonparametric $U$ test was used for analyses of charges and payments owing to lack of normal distribution. Logistic regression models were performed for the use of CPB, 30-day survival, and 90-day readmission. Long-term survival analysis included univariate Kaplan-Meier survival estimates and multivariable Cox proportional hazards analysis. All data management and analysis were performed using SAS version 9.4 (SAS Institute Inc, Cary, NC).

\section{RESULTS}

Baseline characteristics for TAVR patients stratified by access approach are listed in Table 1. The mean patient age was $84 \pm 7$ years, with no significant age differences across the access groups. Compared with TF patients, alternative access patients were more likely to be female and had a greater prevalence of certain comorbidities, including peripheral arterial disease, chronic obstructive 
TABLE 1. Baseline patient characteristics by TAVR access

\begin{tabular}{|c|c|c|c|c|c|c|}
\hline Characteristic & $\begin{array}{c}\text { All TAVR } \\
(n=5030)\end{array}$ & $\begin{array}{c}\text { TA } \\
(n=691)\end{array}$ & $\begin{array}{c}\text { TAO } \\
(n=274)\end{array}$ & $P$ value & $\begin{array}{c}\text { TF } \\
(n=4065)\end{array}$ & $P$ value \\
\hline Age, $y$, mean \pm SD & $83.8 \pm 7.6$ & $83.8 \pm 7.1$ & $83.9 \pm 6.7$ & .8578 & $83.8 \pm 7.7$ & .98 \\
\hline Male sex, \% (n) & $51(2566)$ & $46(317)$ & 45 (124) & .8862 & $52(2125)$ & $<.01$ \\
\hline Black race, $\%(n)$ & $3(166)$ & $2(16)$ & $1(4)$ & .465 & $4(146)$ & .04 \\
\hline Congestive heart failure, $\%(n)$ & $92(4642)$ & $94(648)$ & $93(254)$ & .564 & $92(3740)$ & .26 \\
\hline Peripheral vascular disease, $\%$ (n) & $81(4064)$ & $87(599)$ & $83(227)$ & .1283 & $80(3238)$ & $<.01$ \\
\hline Chronic obstructive pulmonary disease, $(\%) n$ & $57(2884)$ & $62(427)$ & $65(178)$ & .3763 & $56(2279)$ & $<.01$ \\
\hline Diabetes, $\%(n)$ & $25(1281)$ & $27(190)$ & $28(77)$ & .8733 & $25(1014)$ & .21 \\
\hline Renal failure, \% (n) & $53(2645)$ & 57 (396) & 54 (149) & .4287 & $52(2100)$ & .02 \\
\hline Liver disease, \% (n) & $5(243)$ & $5(36)$ & $4(10)$ & .402 & $5(197)$ & .59 \\
\hline Obesity, \% (n) & $20(1007)$ & $18(121)$ & $19(51)$ & .7093 & $21(835)$ & .15 \\
\hline Weight loss (frailty), \% (n) & $13(631)$ & $12(81)$ & $15(40)$ & .2362 & $13(510)$ & .47 \\
\hline
\end{tabular}

$T A V R$, Transcatheter aortic valve replacement; $T A$, transapical; $T A O$, transaortic; $T F$, transfemoral; $S D$, standard deviation.

pulmonary disease, and renal failure. There were significant differences in baseline characteristics the between TA and TAO groups. Overall, 19\% $(\mathrm{n}=965)$ of the patients underwent alternative access TAVR, including $14 \%$ $(\mathrm{n}=691)$ with TA and $5 \%(\mathrm{n}=274)$ with TAO. The relative percentage of patients undergoing alternative access TAVR by quarter fluctuated from $11 \%$ to $46 \%$ during the study period (Figure 1).

Perioperative outcomes are listed in Table 2. Alternative access patients were more likely to require CPB (9\% vs $3 \% ; P<.01)$. Among the alternative access patients, TA patients were more likely than TAO patients to require CPB $(11 \%$ vs $4 \% ; P<.01)$. After adjusting for baseline characteristics, TA patients were more likely to require CPB (odds ratio [OR], 3.6; 95\% confidence interval [CI], 2.7-4.8; $P<.01)$ compared with TAO patients (OR, 1.28; $95 \%$ CI, 0.7-2.3; $P=.42$ ) (Table E2). TF patients had shorter procedure times and intensive care unit (ICU) and hospital lengths of stay. Mortality was also significantly lower in TF compared with TA and TAO $(5.0 \%$ vs $9.6 \%$ vs $8.0 \% ; P<.01)$. The survival difference between $\mathrm{TF}$ and alternative access persisted beyond 1 year (log-rank $P<.01$ ) (Figure 2). There was no difference in unadjusted 30-day or 1-year mortality between TA and TAO. After adjusting for baseline characteristics in a multivariable survival model for 30-day mortality (Table 3), the trend

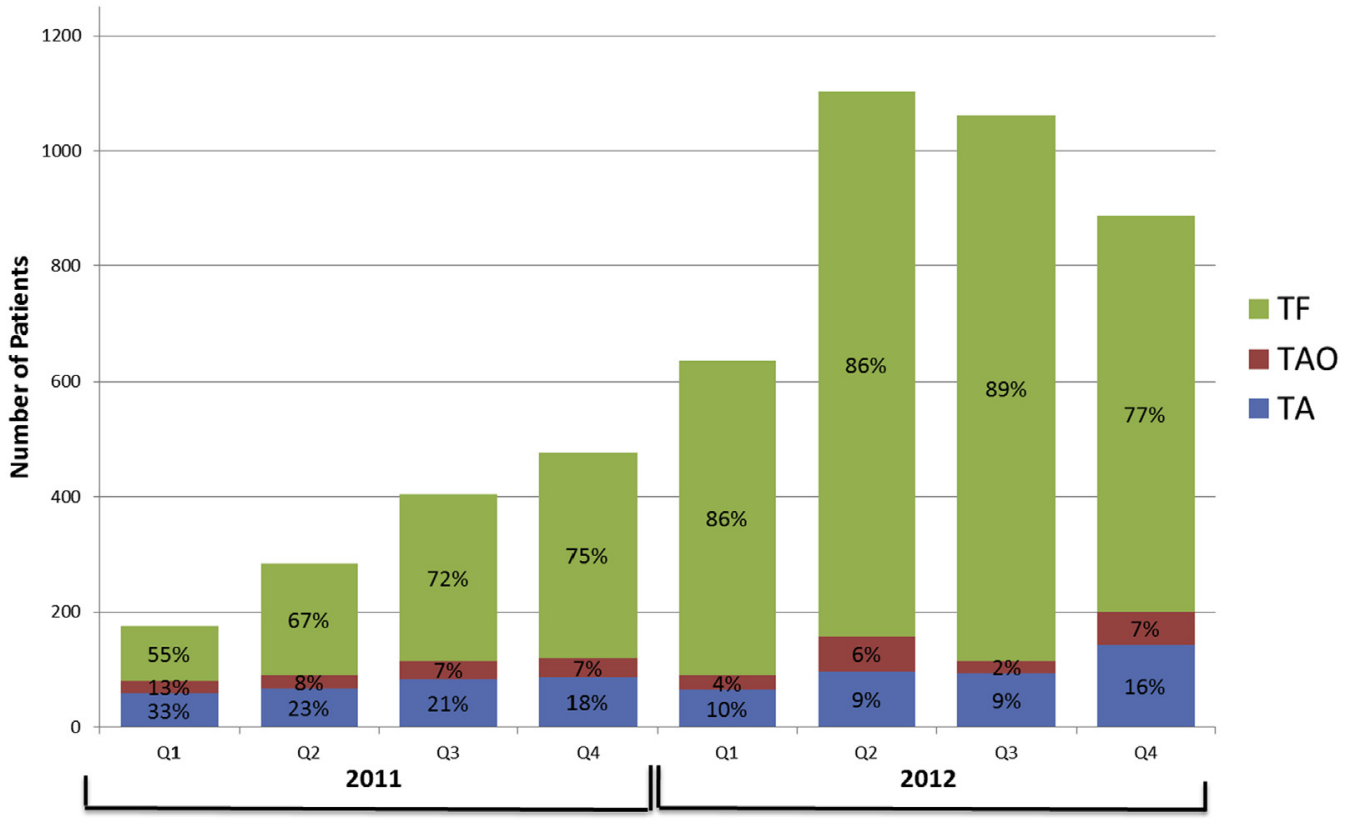

FIGURE 1. Quarterly proportion of TAVR access. $T F$, Transfemoral; TAO, transaortic; $T A$, transapical. 
TABLE 2. Perioperative outcomes by TAVR access route

\begin{tabular}{|c|c|c|c|c|c|c|}
\hline Outcome & $\begin{array}{c}\text { All TAVR } \\
(\mathbf{n}=\mathbf{5 0 3 0})\end{array}$ & $\begin{array}{c}\text { TA } \\
(n=691)\end{array}$ & $\begin{array}{c}\text { TAO } \\
(\mathbf{n}=\mathbf{2 7 4})\end{array}$ & $P$ value & $\begin{array}{c}\text { TF } \\
(n=4065)\end{array}$ & $P$ value \\
\hline $\mathrm{CPB}, \%(\mathrm{n})$ & $5(229)$ & $11(77)$ & $4(12)$ & $<.01$ & $3(140)$ & $<.01$ \\
\hline Postprocedure LOS, d, median (IQR) & $5(4-8)$ & $7(5-10)$ & $7(6-11)$ & .102 & $5(3-7)$ & $<.01$ \\
\hline ICU LOS, d, median (IQR) & $2(0-5)$ & $4(1-8)$ & $4(1-8)$ & .31 & $2(0-4)$ & $<.01$ \\
\hline Early (30-d) mortality, \% (n) & $5.8(292)$ & $9.6(66)$ & $8.0(22)$ & .53 & $5.0(204)$ & $<.01$ \\
\hline
\end{tabular}

$T A V R$, Transcatheter aortic valve replacement; $T A$, transapical; $T A O$, transaortic; $T F$, transfemoral; $C P B$, cardiopulmonary bypass; $L O S$, length of stay; $I Q R$, interquartile range $I C U$, intensive care unit.

toward higher associated mortality in TAO patients did not reach statistical significance (OR, $1.55 ; 95 \%$ CI, 0.97-2.48; $P=.07)$. TA was associated with increased mortality (OR, 1.59 ; $95 \%$ CI $1.17-2.15 ; P<.01)$. In the long-term multivariable survival model, neither TA (hazard ratio [HR], 1.13; 95\% CI, 0.94-1.34; $P=.19$ ) nor TAO (HR, 1.22; $95 \% \mathrm{CI}, 0.95-1.58 ; P=.12$ ) was associated with increased mortality compared with TF.

The use of CPB was associated with significantly higher 30 -day mortality compared with no CPB (23\% vs $5 \%$; $P<.01$ ), and that difference persisted out beyond 1 year (log-rank $P<.01$ ) (Figure 3). In the 30-day multivariable survival model, the strongest predictor of increased mortality was the need for CPB (OR, 5.17; 95\% CI, 3.65-7.32; $P<.01)$. In a long-term Cox survival analysis, the use of CPB persisted as the factor with the strongest association with increased mortality (HR, 2.13; $95 \%$ CI, 1.69-2.7; $P<.01)$. The use of CPB also was associated with increased hospital costs $(\$ 62,000$ [IQR, $\$ 45,100-\$ 86,400]$ vs $\$ 48,800$ [IQR, $\$ 38,100-\$ 62,900]$; $P<.01)$ and increased Medicare payments $(\$ 61,000$ $[\mathrm{IQR}, \$ 44,800-\$ 82,200]$ vs 50,300 [IQR, \$38,200$\$ 65,400] ; P<.01)$.

Discharge outcomes varied by TAVR access, with TF patients more likely to be discharged to home, but also more likely to require home health services compared with alternative access patients (Table E1). TF patients also were the most likely to have no readmissions within 90 days $(52 \%$, vs $50 \%$ for TA and $43 \%$ for TAO; $P=.02$ ). TAO patients were least likely to be discharged to home and had the shortest mean time to first discharge. The overall rate of readmission at 90 days for all TAVR patients was $34 \%$, with no significant differences across the access groups. In a multivariable logistic regression model for 90-day readmission, TAO patients were more likely to be readmitted (OR, 1.32; 95\% CI, 1.00-1.75;

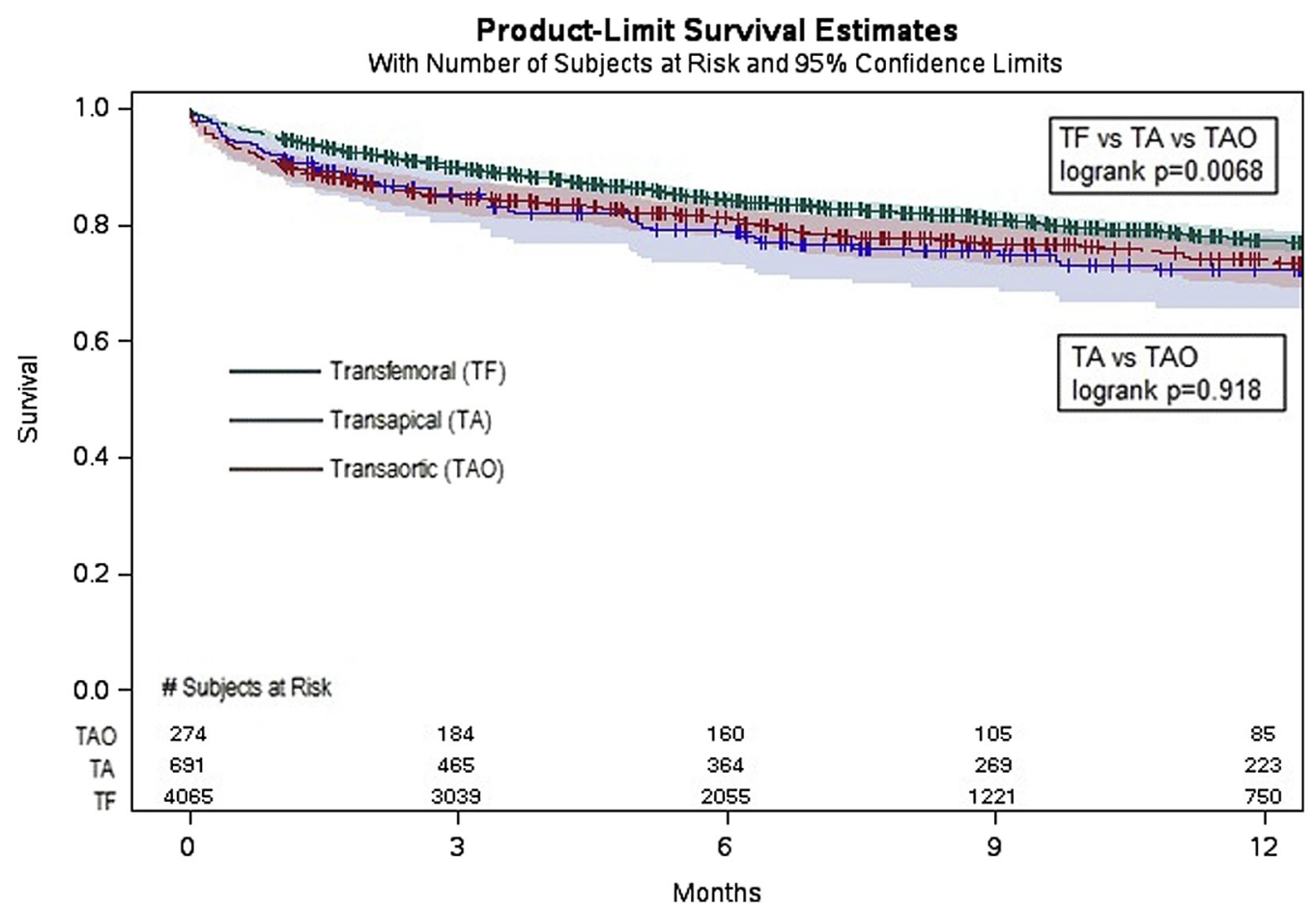

FIGURE 2. Kaplan-Meier survival estimates of TAVR patients by access. $T F$, Transfemoral; $T A$, transapical; TAO, transaortic. 
TABLE 3. Multivariable logistic regression model for 30-day mortality

\begin{tabular}{lcccr}
\hline \multicolumn{1}{c}{ Characteristic } & OR & $\begin{array}{c}\text { Lower } \\
\mathbf{9 5} \% \mathbf{C I}\end{array}$ & $\begin{array}{c}\text { Upper } \\
\mathbf{9 5 \%} \mathbf{C I}\end{array}$ & $\begin{array}{c}\boldsymbol{P} \\
\text { value }\end{array}$ \\
\hline TAO access & 1.55 & 0.97 & 2.48 & .07 \\
TA access & 1.59 & 1.17 & 2.15 & $<.01$ \\
\hline Male sex & 0.93 & 0.73 & 1.19 & .56 \\
\hline White race & 0.90 & 0.54 & 1.48 & .67 \\
\hline Cardiopulmonary bypass & 5.17 & 3.65 & 7.32 & $<.01$ \\
\hline Diabetes & 1.14 & 0.88 & 1.46 & .32 \\
\hline Congestive heart failure & 1.72 & 0.92 & 3.22 & .09 \\
\hline Pulmonary circulation disorder & 1.12 & 0.87 & 1.43 & .39 \\
\hline Peripheral vascular disease & 1.06 & 0.77 & 1.46 & .73 \\
\hline Chronic obstructive & 1.20 & 0.93 & 1.54 & .16 \\
\hline pulmonary disease & & & & \\
\hline Renal failure & 1.50 & 1.15 & 1.95 & $<.01$ \\
\hline Liver disease & 1.87 & 1.19 & 2.94 & .01 \\
\hline Coagulopathy & 1.04 & 0.78 & 1.38 & .81 \\
\hline Obesity & 0.62 & 0.44 & 0.87 & .01 \\
\hline Anemia & 0.99 & 0.75 & 1.29 & .91 \\
\hline Hypertension & 0.83 & 0.40 & 1.70 & .61 \\
\hline Weight loss (frailty) & 1.56 & 1.14 & 2.14 & .01 \\
\hline$O R$, Ords & & &
\end{tabular}

$O R$, Odds ratio; $C I$, confidence interval; $T A O$, transaortic; $T A$, transapical
$P=.05)$, whereas TA access was not associated with a significant increase.

Hospital costs and Medicare payments varied by TAVR access, with TF having the lowest of both, $\$ 48,600$ (IQR, $\$ 37,800-\$ 62,900)$ and $\$ 50,100$ (IQR, $\$ 38,300-\$ 65,600$ ), respectively (Table 4). Variation also existed among specific cost centers, with TF having lower ICU and operating room costs, but higher medical supply costs (Figure E1). At 90 days, there was no statistically significant cost difference between TF $(\$ 52,600$; IQR, $\$ 39,800-\$ 72,200)$ and TAO $(\$ 54,400 ; \quad I Q R, \$ 40,700-\$ 79,500)$, but a significant difference remained between TF and TA $(\$ 57,200$; IQR, $\$ 41,200-\$ 78,100 ; P<.01)$. Although index hospital costs were lower for TA compared with TAO, the difference was no longer significant at 90 days (Table 4). The difference between payments and costs for the index hospitalization was highest for TA $(\$ 5400)$, followed by TAO (\$3700) and then TF $(\$ 1500)$.

\section{DISCUSSION}

There are 4 major findings in this study: 1) TF TAVR was associated with lower 30-day mortality and cost compared with TA or TAO; 2) TA was associated with significantly increased use of $\mathrm{CPB}$; 3 ) intraoperative $\mathrm{CPB}$ was associated with worse outcomes in adjusted and unadjusted analyses

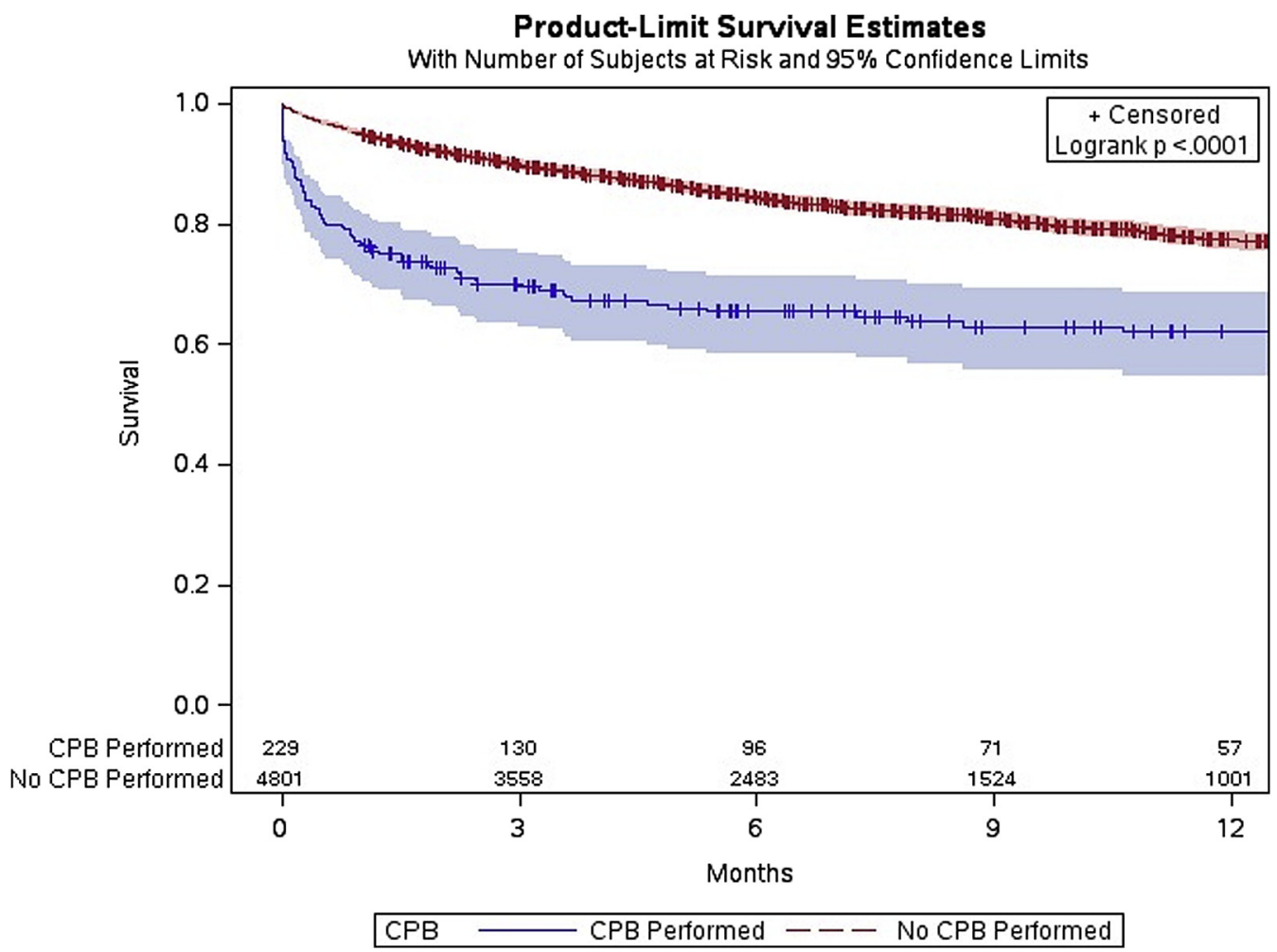

FIGURE 3. Kaplan-Meier survival estimates for TAVR patients by use of CPB. $C P B$, Cardiopulmonary bypass. 
TABLE 4. Hospital Costs and Medicare Payments by TAVR access route

\begin{tabular}{|c|c|c|c|c|c|c|c|}
\hline Cost and payments & $\operatorname{All} \operatorname{TAVR}(n=5030)$ & TA $(n=691)$ & TAO $(n=274)$ & $\begin{array}{c}\text { TAO } \\
\text { vs TA, } \\
P \text { value }\end{array}$ & TF $(n=4065)$ & $\begin{array}{c}\text { TA vs } \mathbf{T F}, \\
P \text { value }\end{array}$ & $\begin{array}{c}\text { TAO } \\
\text { vs TF, } \\
P \text { value }\end{array}$ \\
\hline $\begin{array}{l}\text { 30-d Medicare } \\
\text { payments }\end{array}$ & $\begin{array}{l}\$ 50,700 \\
\quad(\$ 38,600-\$ 66,000)\end{array}$ & $\begin{array}{l}\$ 54,400 \\
\quad(\$ 40,900-\$ 70,900)\end{array}$ & $\begin{array}{l}\$ 56,000 \\
\quad(\$ 43,000-\$ 71,700)\end{array}$ & .30 & $\begin{array}{l}\$ 49,600 \\
\quad(\$ 37,400-\$ 65,000)\end{array}$ & $<.01$ & $<.01$ \\
\hline $\begin{array}{l}\text { 90-d Medicare } \\
\text { payments }\end{array}$ & $\begin{array}{l}\$ 58,200 \\
\quad(\$ 44,200-\$ 85,400)\end{array}$ & $\begin{array}{l}\$ 64,200 \\
\quad(\$ 48,400-\$ 92,200)\end{array}$ & $\begin{array}{l}\$ 67,600 \\
\quad(\$ 48,300-\$ 105,300)\end{array}$ & .287 & $\begin{array}{l}\$ 57,100 \\
\quad(\$ 43,500-\$ 82,800)\end{array}$ & $<.01$ & $<.01$ \\
\hline 30-d hospital cost & $\begin{array}{l}\$ 49,100 \\
\quad(\$ 38,300-\$ 63,800)\end{array}$ & $\begin{array}{l}\$ 49,800 \\
\quad(\$ 40,100-\$ 66,200)\end{array}$ & $\begin{array}{l}\$ 53,200 \\
\quad(\$ 41,100-\$ 68,400)\end{array}$ & .08 & $\begin{array}{l}\$ 48,600 \\
\quad(\$ 37,800-\$ 62,900)\end{array}$ & $<.01$ & .03 \\
\hline 90-d hospital cost & $\begin{array}{l}\$ 53,200 \\
\quad(\$ 40,000-\$ 73,600)\end{array}$ & $\begin{array}{l}\$ 57,200 \\
\quad(\$ 41,200-\$ 78,100)\end{array}$ & $\begin{array}{l}\$ 54,400 \\
\quad(\$ 40,700-\$ 79,500)\end{array}$ & .894 & $\begin{array}{l}\$ 52,600 \\
\quad(\$ 39,800-\$ 72,200)\end{array}$ & $<.01$ & .08 \\
\hline
\end{tabular}

Values are reported as median (interquartile range). $T A V R$, Transcatheter aortic valve replacement; $T A$, transapical; $T A O$, transaortic; $T F$, transfemoral.

and when stratified by TAVR access; and 4) differences in costs and outcomes by access tended to decrease at 90 days compared with those at 30 days.

TF TAVR represents the majority of cases in this study, as well as in other large clinical trials and international registries. In-hospital/30-day mortality for TF TAVR has been reported as $3.7 \%$ to $6.1 \%$ in large randomized trials and $1.1 \%$ in propensity-score matched studies with newer technology, ${ }^{15}$ lower than reported mortality for alternative access TAVR, which has ranged from $7.1 \%-10.3 \%$. ${ }^{1,2,5,16-18}$ Consistent with results of previous TAVR studies, this study had a 30-day mortality of 5.0\% in TF patients, compared with $9.6 \%$ in TA patients and $8.0 \%$ in TAO patients. Reported TA mortality at 30 days in contemporary studies and earlier European registries has ranged from $8.7 \%$ to $10.3 \%{ }^{2,5,17}$

Our findings in the present study capture both clinical trials and early commercial use of TAVR in the United States. Subsequent advances in TAVR technology have already decreased the size of the vascular sheaths required for femoral access, allowing more patients to undergo TF access for TAVR-a trend that will likely only increase going forward. A number of institutions now perform TF TAVR under conscious sedation using a percutaneous approach, further reducing time in the operating room or catheter laboratory, the ICU, and the hospital. Early studies using less invasive approaches have demonstrated at least equivalent outcomes and offer the potential to further offset hospital costs associated with TAVR. ${ }^{19-22}$

Although recent studies have shown a declining use of alternative access, TA and TAO TAVR remain common procedures, with as many as $37 \%$ of patients receiving commercial use alternative access TAVR and $30 \%$ of patients in clinical trials requiring the same. ${ }^{2,6,7}$ Owing to the structure of the clinical trials and Food and Drug Administration approvals, alternative access TAVR patients were first evaluated as potential TF candidates before being considered, and ultimately undergoing, alternative access TAVR. ${ }^{2,23-25}$ Although alternative access TAVR has demonstrated increased in-hospital/ 30-day and 1-year mortality, these patients are generally higher risk or have more comorbidities. ${ }^{5,26}$ This study supports findings of previous studies, with TA and TAO patients having more comorbidities and higher unadjusted mortality than TF patients. TA continued to have higher adjusted mortality than TF, but TAO showed only a trend toward higher mortality that did not reach statistical significance. This finding differs slightly from previous studies that have demonstrated higher mortality for TAO compared with TA, but direct comparisons of TAO and TF TAVR in the United States have been lacking. ${ }^{11}$

One possible explanation for the difference in mortality between TA and other TAVR access routes is the need for CPB. The TA patients in this study were nearly 3 times more likely than TAO or TF patients to CPB. The use of CPB was associated with the greatest increase in mortality in TAVR patients regardless of access route. CPB has been associated with increased mortality in the large clinical trials and commercial use in the United States. ${ }^{6,27,28}$ This study confirms a similar finding of worse outcomes associated with $\mathrm{CPB}$ use, but also provides new information regarding the costs of $\mathrm{CPB}$ to the hospital and to society in the form of Medicare payments. CPB use varied in this study by TAVR access, with TA patients requiring significantly more $\mathrm{CPB}$ use compared with TF and TAO patients, similar to results reported by Thourani and colleagues. ${ }^{11}$ This study also adds to previous studies by evaluating the need for CPB in adjusted survival analysis at both 30 days and $>1$ year and identifying the independent contribution of $\mathrm{CPB}$ as the factor most highly correlated with increased mortality.

Finally, this study provides new information regarding the cost of TAVR in the United States. Previous studies evaluating the cost or cost-effectiveness of TAVR have been limited by the use of modeling and cost extrapolations that have produced mixed results that favor and disfavor TAVR depending on the health system considered and the comparison with either medical management or surgical 
AVR. ${ }^{29-34}$ Reynolds and colleagues found that compared with SAVR, TF TAVR produced favorable cost-effective results, whereas TA TAVR did not. ${ }^{35}$ The present study confirms that TF TAVR produces better results, lower hospital costs, and lower costs to society (Medicare payments) compared with alternative access TAVR. However, these differences do not necessarily persist when readmission and costs out to 90 days are considered. The vast majority of costs for patients were incurred at the index hospitalization, suggesting that these interventions effectively address the patient's primary issue (aortic stenosis) without a degree of clinical or cost burden in the quarter immediately succeeding TAVR.

This study has some limitations. Our analysis was based on administrative claims, which do not directly report institutional costs of care. Hospital-specific cost-to-charge ratios have been previously used to accurately estimate actual costs of care from the total hospital charges reported on inpatient claims. ${ }^{14}$ In addition, the clinical information available on administrative claims is not as rich as data captured in cardiac surgery clinical trials or diseasespecific registries, both of which may provide more detailed patient and procedural information. Thus, we cannot rule out the impact of unmeasured or unreported confounders on the adjusted analyses presented here.

\section{CONCLUSIONS}

Adjusted survival did not differ among the 3 TAVR access routes studied, but TF TAVR demonstrated superior short-term clinical outcomes at lower cost compared with alternative access TAVR. For patients deemed ineligible for TF TAVR, TAO and TA approaches offer similar clinical outcomes at similar cost with acceptable operative and 1-year survival, with the exception of higher rates of CPB use required in the TA approach. The use of CPB was associated with worse survival and increased costs.

\section{Webcast}

You can watch a Webcast of this AATS meeting presentation by going to: http://webcast.aats.org/2016/Video/Wednesday/ 05-18-16_Ballroom_I_0845_McCarthy-800.mp4.

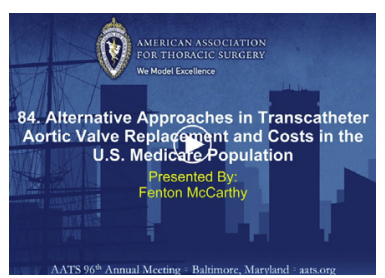

\section{Conflict of Interest Statement}

J.E.B., H.C.H., S.A., W.Y.S., and N.D.D. are investigators in the Edwards Lifesciences PARTNER trial and Medtronic
SURTAVI trial. H.C.H. also receives research funding from Edwards Lifesciences, Medtronic, Boston Scientific, and St Jude Medical and speaking honoraria (consultant) from Edwards LifeSciences. SA serves as an investigator for REPRISE and as a consultant for Medtronic. J.G. receives research funding from St Jude Medical. All other authors have nothing to disclose with regard to commercial support.

\section{References}

1. Leon MB, Smith CR, Mack M, Miller DC, Moses JW, Svensson LG, et al. Transcatheter aortic valve implantation for aortic stenosis in patients who cannot undergo surgery. N Engl J Med. 2010;363:1597-607.

2. Smith CR, Leon MB, Mack M, Miller DC, Moses JW, Svensson LG, et al. Transcatheter versus surgical aortic valve replacement in high-risk patients. N Engl J Med. 2011;364:2187-98.

3. Adams DH, Popma JJ, Reardon MJ, Yakubov SJ, Coselli JS, Deeb GM, et al. Transcatheter aortic-valve replacement with a self-expanding prosthesis. N Engl J Med. 2014;370:1790-8.

4. Popma JJ, Adams DH, Reardon MJ, Yakubov SJ, Kleiman NS, Heimansohn D, et al. Transcatheter aortic valve replacement using a self-expanding bioprosthesis in patients with severe aortic stenosis at extreme risk for surgery. J Am Coll Cardiol. 2014;63:1972-81.

5. Mack MJ, Brennan JM, Brindis R, Carroll J, Edwards F, Grover F, et al. Outcomes following transcatheter aortic valve replacement in the United States. JAMA. 2013;310:2069-77.

6. Holmes DR Jr, Brennan JM, Rumsfeld JS, Dai D, O'Brien SM, Vemulapalli S, et al. Clinical outcomes at 1 year following transcatheter aortic valve replacement. JAMA. 2015;313:1019-28.

7. Leon MB, Smith CR, Mack MJ, Makkar RR, Svensson LG, Kodali SK, et al. Transcatheter or surgical aortic-valve replacement in intermediate-risk patients. N Engl J Med. 2016;374:1609-20.

8. McCarthy FH, Groeneveld PW, Kobrin D, McDermott KM, Wirtalla C, Desai ND. Effect of clinical trial experience on transcatheter aortic valve replacement outcomes. Circ Cardiovasc Interv. 2015;8:e02234.

9. Ludman PF, Moat N, de Belder MA, Blackman DJ, Duncan A, Banya W, et al. Transcatheter aortic valve implantation in the United Kingdom: temporal trends, predictors of outcome, and 6-year follow-up: a report from the UK Transcatheter Aortic Valve Implantation (TAVI) Registry, 2007 to 2012. Circulation. 2015;131: 1181-90.

10. Kornowski R. The alternative approach to transcatheter aortic valve replacement. Catheter Cardiovasc Interv. 2016;87:339-40.

11. Thourani VH, Jensen HA, Babaliaros V, Suri R, Vemulapalli S, Dai D, et al. Transapical and transaortic transcatheter aortic valve replacement in the United States. Ann Thorac Surg. 2015;100:1718-26; discussion 1726-7.

12. van Walraven C, Austin PC, Jennings A, Quan H, Forster AJ. A modification of the Elixhauser comorbidity measures into a point system for hospital death using administrative data. Med Care. 2009;47:626-33.

13. van Hout BA, Al MJ, Gordon GS, Rutten FF. Costs, effects, and C/E-ratios alongside a clinical trial. Health Econ. 1994;3:309-19.

14. Centers for Medicare \& Medicaid Services. MEDPAR Medicare inpatient hospital services: 2008 short stay inpatient by diagnosis-related groups (DRG). Available at: http://www.cms.gov/MedicareFeeforSvcPartsAB/03_MEDPAR. asp. Accessed October 28, 2013.

15. Thourani VH, Kodali S, Makkar RR, Herrmann HC, Williams M, Babaliaros V, et al. Transcatheter aortic valve replacement versus surgical valve replacement in intermediate-risk patients: a propensity score analysis. Lancet. 2016;387:2218-25.

16. Blackstone EH, Suri RM, Rajeswaran J, Babaliaros V, Douglas PS, Fearon WF, et al. Propensity-matched comparisons of clinical outcomes after transapical or transfemoral transcatheter aortic valve replacement: a placement of aortic transcatheter valves (PARTNER)-I trial substudy. Circulation. 2015;131: 1989-2000.

17. Thomas M, Schymik G, Walther T, Himbert D, Lefèvre T, Treede H, et al. Thirty-day results of the SAPIEN Aortic Bioprosthesis European Outcome (SOURCE) Registry: a European registry of transcatheter aortic valve implantation using the Edwards SAPIEN valve. Circulation. 2010;122:62-9.

18. Hamm CW, Möllmann H, Holzhey D, Beckmann A, Veit C, Figulla HR, et al. The German Aortic Valve Registry (GARY): in-hospital outcome. Eur Heart J. 2014; 
35:1588-98.

19. Toggweiler S, Gurvitch R, Leipsic J, Wood DA, Willson AB, Binder RK, et al. Percutaneous aortic valve replacement: vascular outcomes with a fully percutaneous procedure. J Am Coll Cardiol. 2012;59:113-8.

20. Jensen HA, Condado JF, Devireddy C, Binongo J, Leshnower BG, Babaliaros V, et al. Minimalist transcatheter aortic valve replacement: the new standard for surgeons and cardiologists using transfemoral access? J Thorac Cardiovasc Surg. 2015;150:833-9.

21. Mayr NP, Hapfelmeier A, Martin K, Kurz A, van der Starre P, Babik B, et al. Comparison of sedation and general anaesthesia for transcatheter aortic valve implantation on cerebral oxygen saturation and neurocognitive outcome. $\mathrm{Br} J$ Anaesth. 2016;116:90-9.

22. Kadakia MB, Herrmann HC, Desai ND, Fox Z, Ogbara J, Anwaruddin S, et al. Factors associated with vascular complications in patients undergoing balloon-expandable transfemoral transcatheter aortic valve replacement via open versus percutaneous approaches. Circ Cardiovasc Interv. 2014;7: 570-6.

23. US Department of Health and Human Services; Food and Drug Administration. Correspondence regarding premarket approval application for Edwards SAPIEN ${ }^{\mathrm{TM}}$ transcatheter heart valve. November 2, 2011. Available at: http://www.accessdata. fda.gov/cdrh_docs/pdf10/p100041a.pdf. Accessed October 28, 2013.

24. US Food and Drug Administration. FDA expands approved use of SAPIEN artificial heart valve. October 19, 2012. Available at: http://www.fda.gov/NewsEvents/ Newsroom/PressAnnouncements/ucm323478.htm. Accessed October 28, 2013.

25. US Food and Drug Administration. Strengthening our national system for medical device postmarket surveillance. September 2012. Available at: http://www.fda. gov/downloads/AboutFDA/CentersOffices/CDRH/CDRHReports/UCM301924. pdf. Accessed October 28, 2013.

26. Cardiac Interventions Today. FDA approves revised labeling to allow alternative access sites for Edwards SAPIEN TAVR device. September 23, 2013. Available at: http://www.bmctoday.net/citoday.com/2013/08/fda-approves-revised-labelingto-allow-alternative-access-sites-for-edwards-sapien-tavr-device. Accessed October 28, 2013

27. Lardizabal JA, Macon CJ, O'Neill BP, Desai H, Singh V, Martinez CA, et al. Long-term outcomes associated with the transaortic approach to transcatheter aortic valve replacement. Catheter Cardiovasc Interv. 2015; 85:1226-30.

28. Shreenivas SS, Lilly SM, Szeto WY, Desai N, Anwaruddin S, Bavaria JE, et al. Cardiopulmonary bypass and intra-aortic balloon pump use is associated with higher short and long term mortality after transcatheter aortic valve replacement: a PARTNER trial substudy. Catheter Cardiovasc Interv. 2015; $86: 316-22$

29. Reynolds MR, Magnuson EA, Wang K, Lei Y, Vilain K, Walczak J, et al, Cost-effectiveness of transcatheter aortic valve replacement compared with standard care among inoperable patients with severe aortic stenosis: results from the placement of aortic transcatheter valves (PARTNER) trial (Cohort B). Circulation. 2012;125:1102-9.

30. Neyt M, Van Brabandt H, Devriese S, Van De Sande S. A cost-utility analysis of transcatheter aortic valve implantation in Belgium: focusing on a well-defined and identifiable population. BMJ Open. 2012;2:e001032.

31. Osnabrugge RL, Kappetein AP, Reynolds MR, Cohen DJ. Cost-effectiveness of transcatheter valvular interventions: economic challenges. EuroIntervention. 2013:9(Suppl):S48-54.

32. Reynolds MR, Lei Y, Wang K, Chinnakondepalli K, Vilain KA, Magnuson EA, et al. Cost-effectiveness of transcatheter aortic valve replacement with a self-expanding prosthesis versus surgical aortic valve replacement. J Am Coll Cardiol. 2016;67:29-38.

33. Cao C, Liou KP, Pathan FK, Virk S, McMonnies R, Wolfenden H, et al. Transcatheter aortic valve implantation versus surgical aortic valve replacement: meta-analysis of clinical outcomes and cost-effectiveness. Curr Pharm Des. 2016;22:1965-77.

34. Ailawadi G, LaPar DJ, Speir AM, Ghanta RK, Yarboro LT, Crosby IK, et al. Contemporary costs associated with transcatheter aortic valve replacement: a propensity-matched cost analysis. Ann Thorac Surg. 2016;101:154-60; discussion 160

35. Reynolds MR, Magnuson EA, Lei Y, Wang K, Vilain K, Li H, et al. Cost-effectiveness of transcatheter aortic valve replacement compared with surgical aortic valve replacement in high-risk patients with severe aortic stenosis: results of the PARTNER (Placement of Aortic Transcatheter Valves) trial (Cohort A). J Am Coll Cardiol. 2012;60:2683-92.
Key Words: TAVR, cost, transfemoral, transapical, alternative access

\section{Discussion}

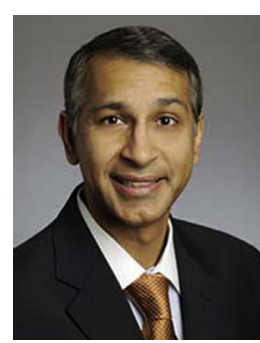

Dr V. Thourani (Atlanta, Ga). I want to thank the Association for the privilege of participating in this invited discussion. It is my pleasure to discuss this very important presentation, and I thank Dr McCarthy for sending me the paper well in advance and congratulate him for an excellent presentation.

We have truly seen a paradigm shift in the management of high- and extreme-risk patients and are on the precipice of really having this procedure in intermediate-risk patients, I think, within the next 6 months. As we have improved the morbidity and mortality, we still have to understand the resource utilization and costs associated with such incredible advancements. In fact, in a paper we are presenting later, we report our readmission rates at 30 days and 1 year.

I have some questions for you. It is hard for us to gauge exactly how sick these patients are since we don't have a EuroSCORE, an STS score, or even a high-risk or extreme-risk categorization attached to this. I do believe that the TA mortality at 30 days of almost $10 \%$ is high, and the question is whether you are really doing TAs on extreme-risk patients and why we are seeing such bad results for that. Can you explain it at all to us? Are we talking about high-risk patients, extreme-risk patients, or patients in an early series?

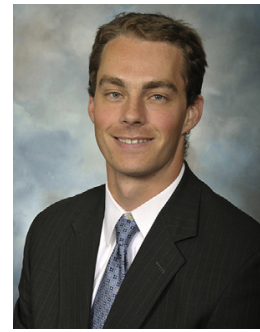

Dr F. McCarthy (Philadelphia, Pa). Thank you. That is a great question. Unfortunately, we don't know the STS or Euro risk score for these patients based on Medicare data. What we do know is that for this cross-section of time-we're talking 2011 and 2012-this was early experience in the United States; a lot of these patients were trial patients or early FDA approval. So the 10\% TA mortality rate is within range of the early TVT and early PARTNER studies, as well as other international registries.

What we could say is that this represents the highest risk of TAVR as well as a bit of an early experience with the technology.

Dr Thourani. The CPB aspect of it puzzles me. We have less than a $1 \%$ use of CPB with transapicals, and what you are presenting in your series is pretty high; 1 out of 10 patients is going to be on cardiopulmonary bypass. I do notice that when I put a patient on bypass who had a TA, 
the chance of mortality was exceedingly high, and I agree with that.

Is there any way for us in the room to tease out who is that patients who are going to require $\mathrm{CPB}$ and maybe not doing it when they are getting CPR and you are trying to cannulate them but a little bit earlier on? Do you have any sense or any factors that we can figure out what would help us not put that patient on $\mathrm{CPB}$ ?

Dr McCarthy. I think the strongest thing we could say from this study is that if a patient is not a transfemoral candidate, you should consider a transaortic approach. The transapical approach was most likely to be associated with cardiopulmonary bypass. I think the high rate of cardiopulmonary bypass is also somewhat reflective of the early experience in 2 respects, both learning the technology and provider comfort with the technology and that people might be a little more likely to put patients on cardiopulmonary bypass rather than resuscitate them aggressively. I think those 2 factors are important in terms of understanding the rate of cardiopulmonary bypass. I don't think, though, that you can take that away from the fact that the people who ended up getting it really did significantly worse.

Your point is really germane in the sense that when these patients undergo their preoperative workup and you are deciding which approach you are going to consider, the sicker patient, the patient that has pulmonary hypertension, maybe some mitral regurgitation, another few factors that we can't absolutely capture here but you might know when you are evaluating that individual patient, choosing the approach that is less likely to put them on cardiopulmonary bypass is important.

Dr Thourani. With the advent of the newer iterations leading to the SAPIEN 3 and the Evolut devices in 90\% of patients, do we need to just stop doing alternative access? Should we just go to transcaval and do trans-subclavian and just forget the TA and the TAO? I am not sure I personally believe that, but I would love your thoughts on this provocative question.

Dr McCarthy. I think I am probably underqualified to answer that in terms of the people who are in this room, but in terms of what I would say is that I think it is important to keep in mind that this probably isn't the last transcatheter technology for structural heart valve disease. So when we consider approaches, I think the lesson to take way from this is although TAVR might evolve into smaller devices like we have already seen, SAPIEN 3 has a much higher percentage of $\mathrm{TF}$ than previous iterations, and new technologies might require some approach that is different than TF. And like you say, it might not be transapical, it might not be transaortic, but we should continue to evaluate the factors associated with alternative access that set patients up for worse outcomes.

Readers who found these articles interesting may also like to read the following papers found in recent and future issues of our sister publications, Seminars in Thoracic and Cardiovascular Surgery and Operative Techniques in Thoracic and Cardiovascular Surgery!

Acquired: Aortic Valve

STATE OF THE ART: Sutureless Sorin Perceval Aortic Valve Implantation. Steffen Pfeiffer. Semin Thoracic Surg 2017: In press. ORIGINAL SUBMISSION: How to Perform a Simplified Technique for Transapical Aortic Valve Implantations. Pierre-Yves Litzler. Oper Tech Thorac Cardiovasc 2016: In press.

ORIGINAL SUBMISSION: Phase of Care Mortality Analysis: A Unique Method for Comparing Mortality Differences Among Transcatheter Aortic Valve Replacement and Surgical Aortic Valve Replacement Patients. Todd C. Crawford. Semin Thoracic Surg 2016: $245-252$.

ORIGINAL SUBMISSION: Sutureless Aortic Valves: Combining the Best or the Worst? Kareem Bedeir. Semin Thoracic Surg 2016: 341-352.

ORIGINAL SUBMISSION: Comparison of Aortic Annulus Dimension after Aortic Valve neocuspidization with valve replacement and normal valve. Yoshitaka Yamamoto. Semin Thoracic Surg 2017: In press. 
Median Resource Specific Cost for TA vs. TAO vs. TF Patients

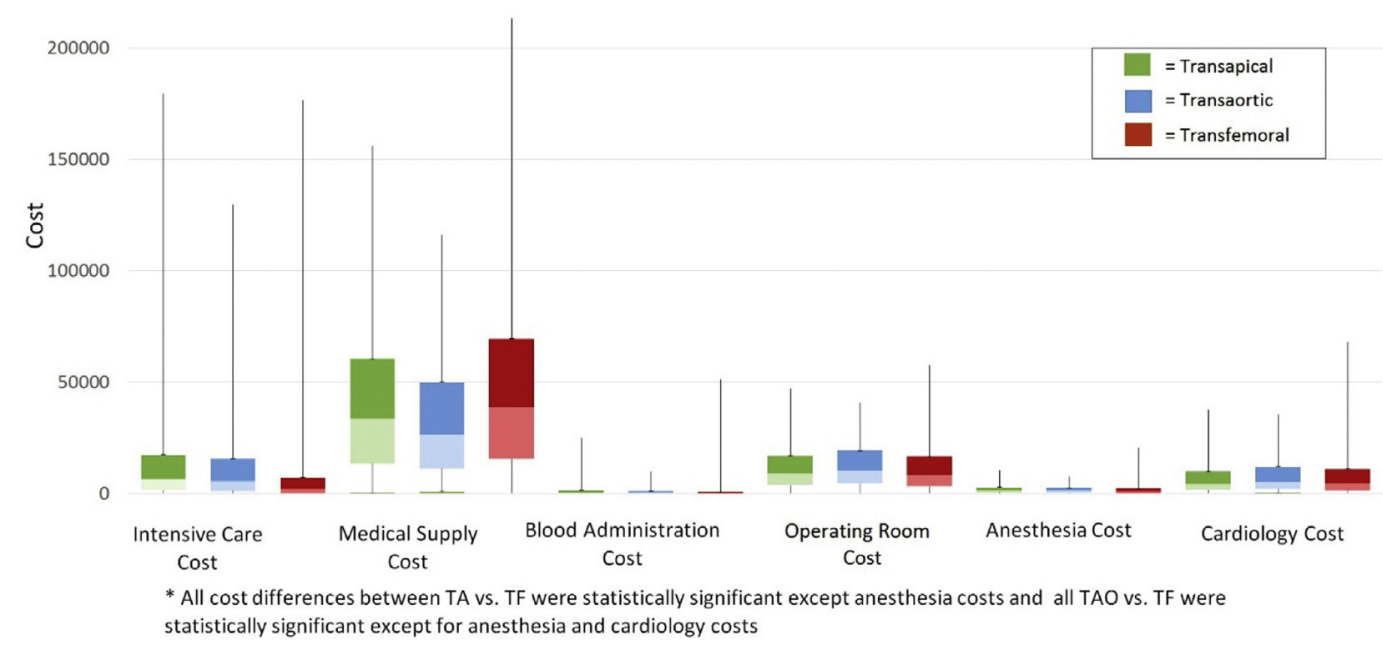

FIGURE E1. Median resource-specific costs by TAVR access. TA, Transapical; $T A O$, transaortic; $T F$, transfemoral.

TABLE E1. Discharge and readmission by TAVR access route

\begin{tabular}{lcccccc}
\hline \multicolumn{1}{c}{ Discharge destination } & All TAVR & TA & TAO & $\boldsymbol{P}$ value & TF & $\boldsymbol{P}$ value \\
\hline Discharge to home, \% (n) & $30(1505)$ & $27(185)$ & $18(50)$ & $<.01$ & $31(1270)$ & $<.01$ \\
Discharge to home with care from an organized home health service, \% (n) & $31(1581)$ & $27(184)$ & $30(82)$ & .30 & $32(1315)$ & $<.01$ \\
Discharge to a skilled nursing facility, \% (n) & $25(1247)$ & $26(182)$ & $30(81)$ & .31 & $24(984)$ & .08 \\
Discharged/transferred to an inpatient rehabilitation facility, $(\%) \mathrm{n}$ & $7(333)$ & $9(65)$ & $11(31)$ & .37 & $6(237)$ & $<.01$ \\
\hline
\end{tabular}

$T A V R$, Transcatheter aortic valve replacement; $T A$, transapical; $T A O$, transaortic; $T F$, transfemoral.

TABLE E2. Logistic model predicting CPB in TAVR patients

\begin{tabular}{|c|c|c|c|c|}
\hline Characteristics & OR & Lower $95 \%$ CI & Upper $95 \%$ CI & $P$ value \\
\hline Male sex & 0.77 & 0.58 & 1.02 & .07 \\
\hline White race & 1.99 & 0.92 & 4.30 & .08 \\
\hline Transaortic & 1.28 & 0.70 & 2.35 & .42 \\
\hline Transapical & 3.59 & 2.67 & 4.83 & $<.01$ \\
\hline Diabetes & 1.16 & 0.88 & 1.54 & .30 \\
\hline Congestive heart failure & 1.77 & 0.91 & 3.41 & .09 \\
\hline Pulmonary circulation disorder & 1.51 & 1.14 & 1.99 & $<.01$ \\
\hline Peripheral vascular disease & 1.36 & 0.93 & 1.99 & .12 \\
\hline Chronic obstructive pulmonary disease & 0.83 & 0.63 & 1.10 & .19 \\
\hline Renal failure & 0.95 & 0.71 & 1.26 & .70 \\
\hline Liver disease & 0.97 & 0.51 & 1.83 & .92 \\
\hline Coagulopathy & 1.04 & 0.75 & 1.45 & .80 \\
\hline Obesity & 1.28 & 0.92 & 1.78 & .15 \\
\hline Anemia & 0.75 & 0.56 & 1.00 & .05 \\
\hline Hypertension & 0.43 & 0.22 & 0.83 & .01 \\
\hline Weight loss & 1.61 & 1.11 & 2.31 & .01 \\
\hline
\end{tabular}

$O R$, Odds ratio; $C I$, confidence interval. 